\title{
Biodiesel Feedstock Production from Freshwater Microalgae Grown in Sugarcane Juice Hydrolysate
}

\author{
Supaporn Kookkhunthod, Rattanaporn Baojungharn, and Ratanaporn Leesing
}

\begin{abstract}
Microalgae have the potential to generate significant quantities of biomass and lipid suitable for biodiesel preparation. Heterotrophic growth of microalgae involves the utilization of organic compounds as sole carbon and energy sources under dark condition that could get rid of the dependence on light. In this work, lipid as biodiesel feedstock production from batch heterotrophic cultivation of freshwater microalgae Chlorella sp. KKU-S2 by using sugarcane thick juice hydrolysate as carbon substrate ( $\mathrm{SJH}$ ), different nitrogen source and concentrations, different concentration of carbon substrate were investigated. Among the nitrogen sources tested, yeast extract supported the maximum biomass while $\mathrm{NaNO}_{3}$ support the maximum lipid yield thus, with respect to the high lipid productivity, $\mathrm{NaNO}_{3}$ was selected as nitrogen source. Using $1.0 \mathrm{~g} / \mathrm{L}$ of $\mathrm{NaNO}_{3}$ as inorganic nitrogen source, the maximum biomass yield of $11.60 \mathrm{~g} / \mathrm{L}$ with biomass productivity of $1.45 \mathrm{~g} / \mathrm{L} / \mathrm{d}$ was obtained using $20 \mathrm{~g} / \mathrm{L} \mathrm{SJH}$. The maximum lipid yield of $2.55 \mathrm{~g} / \mathrm{L}$ with lipid productivity of $0.32 \mathrm{~g} / \mathrm{L} / \mathrm{d}$ was obtained when $50 \mathrm{~g} / \mathrm{L} \mathrm{SJH}$ was used. Maximum process product yield $\left(Y_{P / S}\right)$ of 0.26 was obtained when $\mathrm{SJH}$ concentration was 50 g/L.
\end{abstract}

Index Terms-Biodiesel feedstock, Chlorella sp. KKU-S2, heterotrophic growth, sugarcane thick juice.

\section{INTRODUCTION}

Microalgae-derived biodiesel have emerged as one of the most promising alternative sources of lipid for use in biodiesel production because of their high lipid content, higher growth rates and productivity compared to conventional cropsand microalgae do not compete for land with crops used for food production and other products [1], [2]. Microalgae are a diverse and metabolically flexible group such as photoautotrophic, heterotrophic and mixotrophic growths [2], [3]. Majority of the microalgae strains are photoautotrophic in nature and can be cultivated either in open ponds or closed system in photobioreactors using $\mathrm{CO}_{2}$ and light as carbon and energy sources, respectively [4], this culture mode presents several

Manuscript received September 23, 2014; revised June, 2015. This work was supported by the Higher Education Research Promotion and National Research University (NRU) Project of Thailand, Office of the Higher Education Commission, through the Biofuel Cluster of Khon Kaen University and Khon Kaen University (KKU) Research Fund, fiscal years 2011-2013. Grant for traveling support from Graduate School of Khon Kaen University is gratefully acknowledged.

Supaporn Kookkhunthod and Rattanaporn Baojungharn are with the Graduate School of Khon Kaen University, Thailand (e-mail: Supaporn.kookkhunthod.mam@gmail.com, birdjidrid@gmail.com).

Ratanaporn Leesing is with the Department of Microbiology, Faculty of Science and Alternative Energy Research and Development (AERD) and Fermentation Research Center for Value Added Agricultural Products (FerVAAP) Khon Kaen University, Khon Kaen 40002, Thailand (e-mail: ratlee@kku.ac.th). disadvantages including low biomass productivity, low lipid content and long periods of cultivation. Hence, heterotrophic and mixotrophic cultures have been proposed as feasible alternatives for the production of biomass and cellular lipid accumulation [5].

Mixotrophic cultures of microalgae have an edge over photoautotrophic cultures as they have two energy sources as organic carbon source and light, they can simultaneously drive photoautotrophic and heterotrophic to utilize both inorganic $\left(\mathrm{CO}_{2}\right)$ and organic carbon substrates [6], [7]. While, heterotrophic growth of microalgae involves the utilization of organic compounds as sole carbon and energy sources under dark condition that could get rid of the dependence on light [8]. Based on different microalgae and culture conditions such as temperature, nutrient and light intensity, lipid content and fatty acid composition are varied, the cellular lipid content in various classes of microalgae was improved significantly under stress conditions, such as nitrogen starvation and phosphate limitation [9], [10].

The microalgae Chlorella sp., especially $C$. protothecoides and $C$. vulgaris are two widely available microalgae strains in the commercial applications [11]. Chlorella sp. KKU-S2 is a freshwater microalgae found in the area of Khon Kaen, northeastern of Thailand [12], can grow under photoautotrophic, heterotrophic and mixotrophic conditions and the most fatty acids produced by these strain are palmitic acid, stearic acid, oleic acid and linoleic acid which a suitable feedstock for biodiesel production. Nowadays, the production cost of microalgae-derived biodiesel is much higher than that of diesel derived from petroleum fossil fuel due to the lower culture process efficiency and higher cost of biodiesel feedstock production is mainly contributed by microalgae cultivation including biomass, lipid accumulation and extraction is essential step as feedstock takes up to $70 \%$ of the overall cost [13], [14].

Heterotrophic cultures of microalgae have been reported using different carbon sources, such as glucose, sucrose, glycerol and molasses [15], [16]. However, glucose is most commonly used for sustaining microalgae growing in the dark of several microalgal species reaching high biomass and lipids productivity [17]-[19], thus the use of this substrate result to high production costs of microbial lipid.Theuse of cost-effective carbon substrate containing sugar is needed. Sugarcane thick juice containing high concentration of sugar as mainly sucrose about $57.3 \%(\mathrm{w} / \mathrm{w}), 10.7 \%(\mathrm{w} / \mathrm{w})$ glucose and $4.0 \%(\mathrm{w} / \mathrm{w})$ fructose [20] could be used as alternative carbon substrate for heterotrophic microalgae cultivation, which could lower the production cost and make biodiesel more profitable. Therefore, in this work, biomass and lipid productions from heterotrophic growth of microalgae Chlorella sp. KKU-S2 in low-cost industrial feedstock, 
sugarcane thick juicewas performed, which were then subsequently used for biodiesel feedstock.

\section{MATERIALS AND METHODS}

\section{A. Carbon Substrate, Microalgae and Culture Conditions}

The carbon substrate used in this study was sugarcane thick juice collected from a local market in Khon Kaen province, Thailand. The pre-treated sugarcane thick juice was mixed with sulfuric acid for final concentration of $1 \%(\mathrm{v} / \mathrm{v})$ and then, the mixture was treated in water baht at $100^{\circ} \mathrm{C}$ for $40 \mathrm{~min}$. To remove insoluble particles, the liquid fraction as sugarcane thick juice hydrolysate ( $\mathrm{SJH})$ was separated by centrifugation particles then neutralized by adding $5 \mathrm{~N} \mathrm{NaOH}$ and then stored at $4^{\circ} \mathrm{C}$ prior to use. The reducing sugar of $\mathrm{SJH}$ was analyzed by DNS method and adjusted the reducing sugar to obtain desirable concentration for used as the carbon source.

The microalgae Chlorella sp. KKU-S2 used in this study was isolated from freshwater taken from pond in the area of Khon Kaen province, northeastern Thailand [12]. Active cultures for inoculation were obtained in $250 \mathrm{~mL}$ Erlenmeyer flasks with $100 \mathrm{~mL}$ of Bristol's medium supplemented with $20 \mathrm{~g} / \mathrm{L}$ reducing sugar of sugarcane thick juice hydrolysate. The seed culture was pre-cultivated onto Bristol's medium supplemented with $20 \mathrm{~g} / \mathrm{L}$ glucose at $30^{\circ} \mathrm{C}$ in an incubator shaker at a shaking speed of $150 \mathrm{rpm}$ for 3 days. The Bristol's medium contained the following components (mg/L): $\mathrm{NaNO}_{3}$ 250, $\mathrm{K}_{2} \mathrm{HPO}_{4} 75, \mathrm{KH}_{2} \mathrm{PO}_{4} 175, \mathrm{CaCl}_{2} \quad 25, \mathrm{NaCl} 25$, $\mathrm{MgSO}_{4} .7 \mathrm{H}_{2} \mathrm{O} 75$, and $\mathrm{FeCl}_{2} 0.3, \mathrm{MnSO}_{4} \cdot 2 \mathrm{H}_{2} \mathrm{O} 0.3, \mathrm{ZnSO}_{4}$ $7 \mathrm{H}_{2} \mathrm{O} 0.2, \mathrm{H}_{3} \mathrm{BO}_{3} 0.2, \mathrm{CuSO}_{4} .5 \mathrm{H}_{2} \mathrm{O} 0.06$, and $\mathrm{pH}$ was adjusted to 6.0 before sterilization.

Batch cultivations were performed in $250 \mathrm{~mL}$ Erlenmeyer flasks, each containing $100 \mathrm{~mL}$ of medium supplemented with sugarcane thick juice hydrolysate, flasks were inoculated with $10 \%(\mathrm{v} / \mathrm{v})$ seed culture and cultivated in an incubator rotary shaker set to $150 \mathrm{rpm}$ at $30^{\circ} \mathrm{C}$ for 8 days under dark condition for heterotrophic growth. Periodic samples were taken from the flasks to determine the cell biomass and lipid yields, which were then used to calculate the biomass and lipid productivities.

\section{B. Measurement of Cell Growth, Residual Sugar and Lipid Yields}

Cell growth of Chlorella sp. KKU-S2 was determined by optical density reading at $680 \mathrm{~nm}\left(\mathrm{OD}_{680}\right)$. A standard curve was prepared by plotting dry cell weight $(\mathrm{DCW})$ values $(\mathrm{g} / \mathrm{L})$ against corresponding optical density $\left(\mathrm{OD}_{680}\right)$ readings by using spectrophotometer. A linear regression fit was obtained for dry cell weight (DCW) of Chlorella sp. KKU-S2 as a function of $\mathrm{OD}_{680}, y=1.9039 x+2.2149, R^{2}=0.9964$. There was a direct correlation between optical density and dry cell weight.

The culture broth was centrifuged at 5,000 rpm for $5 \mathrm{~min}$ then the supernatant was analyzed for residual sugar concentration according to DNS method [21]. Harvested biomass was washed twice with $5 \mathrm{~mL}$ of distilled water and cellular lipids were determined by the modified method of Kwon and Rhee [22]. Biomass and Lipid productivities were calculated.
Biomass productivity $(\mathrm{g} / \mathrm{L} / \mathrm{d})$ during the culture period was calculated from the Eq. (1), where $X_{t}$ was the biomass yield $(\mathrm{g} / \mathrm{L})$ at the end of growth phase $\left(t_{t}\right)$ and $X_{0}$ the initial biomass yield $(\mathrm{g} / \mathrm{L})$ at $t_{0}$ (day),

$$
\text { Biomass productivity }=\left(X_{t}-X_{0}\right) /\left(t_{t}-t_{0}\right)
$$

Lipid productivity $(\mathrm{g} / \mathrm{L} / \mathrm{d})$ at the end of cultivation was calculated from the Eq. (2), where $P_{t}$ was the lipid yield $(\mathrm{g} / \mathrm{L})$ at the end of growth phase $\left(t_{t}\right)$ and $P_{0}$ the initial lipid yield $(\mathrm{g} / \mathrm{L})$ at $t_{0}($ day $)$

$$
\text { Lipid productivity }=\left(P_{t}-P_{0}\right) /\left(t_{t}-t_{0}\right)
$$

Process product yield $\left(Y_{P / S}\right)$ at the end of cultivation was calculated from Eq. (3), where $P$ was lipid yield (g/L) and $S$ (g/L) was consumed glucose,

$$
Y_{P / S}=\text { lipid yield/consumed carbon substrate }
$$

The specific growth rate $(\mu)$ is the slope determined by plotting the natural $\log$ of biomass versus time for each substrate concentration during the initial phase of exponential growth before the substrate concentration decreases significantly, while specific rate of lipid production $(q P)$ was a multiple of $\mu$ and $Y_{P / X}$.

\section{RESULTS AND DISCUSSION}

\section{A. Effect of Different Types of Nitrogen Source on Growth and Lipid Production}

It has been reported that different types and concentrations of nitrogen sources had varied influence on cellular lipid accumulation. Therefore, effects of different types of nitrogen sources with initial concentration of $1.0 \mathrm{~g} / \mathrm{L}$ on growth and cellular lipid production of Chlorella sp. KKU-S2 were tested. During the first four days of cell growth, cell density as biomass concentration exponentially increased. Lipid accumulation was promoted after day four of cultivation time.

As shown in Fig. 1, among the nitrogen sources tested, yeast extract supported the maximum biomass of $12.7 \mathrm{~g} / \mathrm{L}$ with biomass productivity of $1.59 \mathrm{~g} / \mathrm{L} / \mathrm{d}$ while $\mathrm{NaNO}_{3}$ support the maximum lipid yield of $2.25 \mathrm{~g} / \mathrm{L}$ d with lipid productivity of $0.28 \mathrm{~g} / \mathrm{L} / \mathrm{d}$. A biomass yield of $9.4,10.9,8.2,9.3,12.4$, $6.6 \mathrm{~g} / \mathrm{L}$ with biomass productivity of $1.18,1.36,1.03,1.16$, $1.55,0.83 \mathrm{~g} / \mathrm{L} \mathrm{d}$ were observed when $\mathrm{NaNO}_{3}, \mathrm{KNO}_{3}$, $\left(\mathrm{NH}_{4}\right)_{2} \mathrm{SO}_{4}$, peptone, malt extract and urea were used, respectively.

Lipid yield of $2.2,1.26,1.0,1.72,1.41$ and $0.76 \mathrm{~g} / \mathrm{L}$ with lipid productivity of $0.28,0.16,0.13,0.22,0.18$ and $0.10 \mathrm{~g} / \mathrm{L} /$ $\mathrm{d}$ were obtained when using $\mathrm{KNO}_{3},\left(\mathrm{NH}_{4}\right)_{2} \mathrm{SO}_{4}$, peptone, yeast extract, malt extract and urea as nitrogen sources. It is worth mentioning that the organic substrate played an important role in promoting biomass accumulation of Chlorella sp. KKU-S2 during heterotrophic cultivation. Wu et al. (2014) showed that potassium nitrate was the suitable nitrogen source for both cell growth and lipid accumulation of Monoraphidium sp. SB2 under the photoautotrophic conditions [23]. However, in this study, with respect to the high lipid productivity, $\mathrm{NaNO}_{3}$ was selected as nitrogen source for further study. 

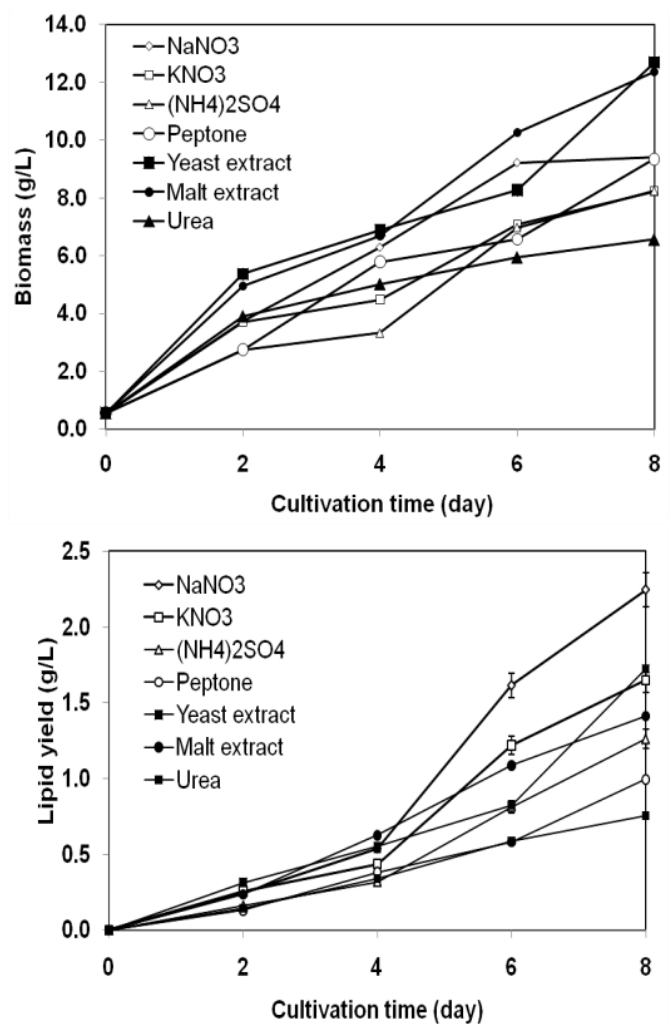

Fig. 1. Time course of cell growth and lipid accumulation of heterotrophic cultivation of Chlorella sp. KKU-S2 on Bristol's medium supplemented with $\mathrm{SJH}$ as carbon substrate with different types of nitrogen sources, cultivated at $30^{\circ} \mathrm{C}$ for 8 days.

\section{B. Effect of Nitrogen Concentration on Growth and Lipid Production}

According to the above results, $\mathrm{NaNO}_{3}$ was selected as nitrogen source. As shown in Fig. 2, higher initial nitrogen concentrations of the culture medium led to an increase in biomass concentration, the cell growth with $1.0 \mathrm{~g} / \mathrm{LNaNO}_{3}$ is much better than others, the highest biomass yield of $7.52 \mathrm{~g} / \mathrm{L}$ with biomass productivity of $0.94 \mathrm{~g} / \mathrm{L} / \mathrm{d}$. In the experimental data, an increase in an initial concentration of $\mathrm{NaNO}_{3}$ in the culture medium led to a decrease in lipid yield, the highest lipid yield of $1.20 \mathrm{~g} / \mathrm{L}$ with lipid productivity of $0.15 \mathrm{~g} / \mathrm{L} / \mathrm{d}$ was obtained when initial concentration of $\mathrm{NaNO}_{3}$ was $1.0 \mathrm{~g} / \mathrm{L}$.

The lipid productivity decreased as $\mathrm{NaNO}_{3}$ concentration increased from 2.0 to $5.0 \mathrm{~g} / \mathrm{L}$, lipid yield of $0.93,0.81,0.84$ and $0.74 \mathrm{~g} / \mathrm{L}$ with lipid productivity of $0.12,0.10, .010$ and $0.09 \mathrm{~g} / \mathrm{L} / \mathrm{d}$ were obtained when initial $\mathrm{NaNO}_{3}$ was $2,3,4$ and $5 \mathrm{~g} / \mathrm{L}$, respectively. Consequently, initial concentration of
$\mathrm{NaNO}_{3}$ at $1.0 \mathrm{~g} / \mathrm{L}$, was considered to be appropriated to achieve high lipid productivity.
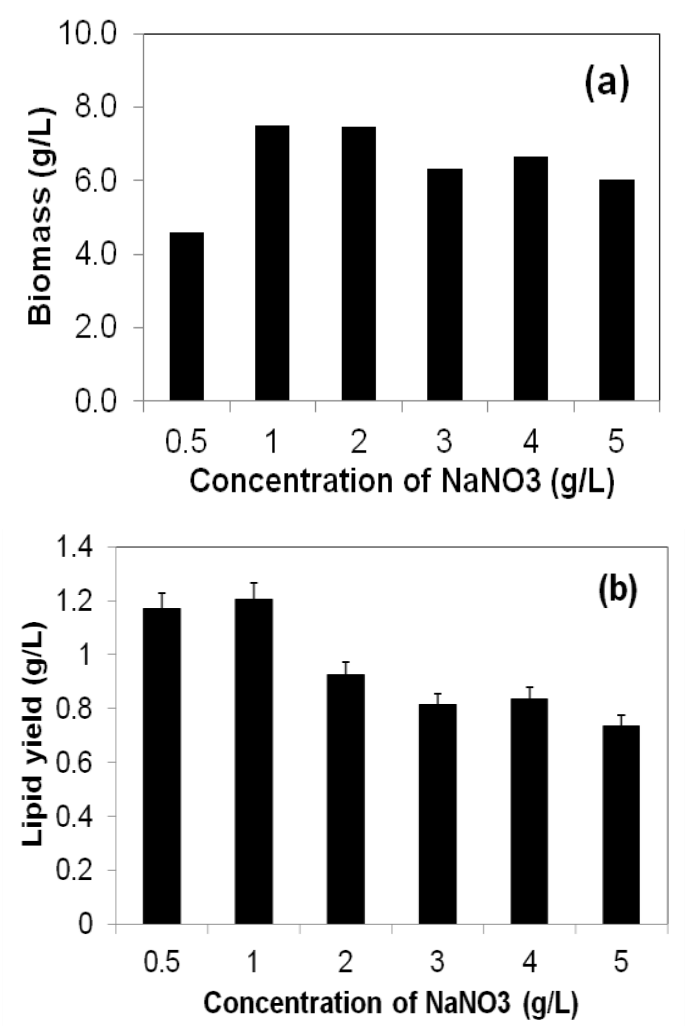

Fig. 2. Effect of $\mathrm{NaNO}_{3}$ concentration on biomass (a) and lipid yields (b) of heterotrophic growth of Chlorella sp. KKU-S2 on Bristol's medium supplemented with $\mathrm{SJH} 20 \mathrm{~g} / \mathrm{L}$ as carbon substrate at day 8 of cultivation time.

\section{Effect of SJH Concentration on Growth and Lipid Production}

To investigate the effect of SJH concentration on growth and lipid accumulation, batch cultures with $1.0 \mathrm{~g} / \mathrm{L} \mathrm{NaNO}_{3}$ were carried out with different concentration of SJH. As shown in Table I, both of biomass and lipid yields increased gradually with the increase of $\mathrm{SJH}$ from 5 to $30 \mathrm{~g} / \mathrm{L}$ and decreased of biomass at $40 \mathrm{~g} / \mathrm{L} \mathrm{SJH}$, and high specific growth rate $(\mu, / d)$ was observed of about $0.30-0.31$ when Chlorella sp. KKU-S2 grown on medium supplemented with 10-40 $\mathrm{g} / \mathrm{LSJH}$. The high biomass yield of $11.60 \mathrm{~g} / \mathrm{L}$ with biomass productivity of $1.45 \mathrm{~g} / \mathrm{L} \mathrm{d}$ was obtained using $20 \mathrm{~g} / \mathrm{L} \mathrm{SJH}$. The cellular lipid yield was quite low at low level of $\mathrm{SJH}$ concentration, then showed an increase when $\mathrm{SJH}$ concentration increased.

TABLE I: KinETIC PARAMETERS OF HeTEROTROPHIC GROWTH OF MiCROALGAE CHLORELLA SP. KKU-S2 ON BRISTOL'S MEDIUM SUPPLEMENTED WITH DiFFERENT CONCENTRATION OF SJH, 1.0G/L NANO 3 AT DAY 8 OF CULTIVATION TIME AT 30 C, 150 RPM

\begin{tabular}{|c|c|c|c|c|c|c|c|c|}
\hline \multirow[b]{2}{*}{ Kinetic parameters } & \multicolumn{8}{|c|}{ " SJH concentration (g/L) } \\
\hline & 5 & 10 & 20 & 30 & 40 & $\mathbf{5 0}$ & 60 & 70 \\
\hline$X(\mathrm{~g} / \mathrm{L})$ & 2.19 & 4.61 & 11.60 & 11.50 & 10.60 & 9.70 & 6.30 & 3.00 \\
\hline$P(\mathrm{~g} / \mathrm{L})$ & 0.35 & 1.18 & 2.24 & 2.27 & 2.42 & 2.55 & 1.47 & 0.67 \\
\hline$\mu(1 / \mathrm{d})$ & 0.23 & 0.29 & 0.31 & 0.31 & 0.30 & 0.28 & 0.23 & 0.14 \\
\hline$Q_{X}(\mathrm{~g}$ cells $/ \mathrm{L} / \mathrm{d})$ & 0.27 & 0.58 & 1.45 & 1.44 & 1.33 & 1.21 & 0.79 & 0.38 \\
\hline$Q_{P}(\mathrm{~g} / \mathrm{L} / \mathrm{d})$ & 0.04 & 0.15 & 0.28 & 0.28 & 0.30 & 0.32 & 0.18 & 0.08 \\
\hline$Y_{P / S}(\mathrm{~g}$ lipid/g substrate) & 0.06 & 0.11 & 0.19 & 0.20 & 0.23 & 0.26 & 0.23 & 0.23 \\
\hline$q_{P}(\mathrm{~g}$ lipid $/ \mathrm{g}$ cells/d $)$ & 0.04 & 0.08 & 0.06 & 0.06 & 0.07 & 0.07 & 0.05 & 0.03 \\
\hline
\end{tabular}


The maximum lipid yield of $2.55 \mathrm{~g} / \mathrm{L}$ with lipid productivity of $0.32 \mathrm{~g} / \mathrm{L} \mathrm{d}$ was obtained when $50 \mathrm{~g} / \mathrm{L} \mathrm{SJH}$ was used. Further increase in $\mathrm{SJH}$ concentration beyond 60 resulted in a slight drop in lipid content and biomass, suggesting that a considerable carbon substrate inhibitory effect had occurred.

Liang et al. [24] reported that, Chlorella vulgaris showed improved biomass production in $1 \%$ and $2 \%$ glucose while $5 \%$ and $10 \%$ were inhibitory. Cultivation of microalgae, when nitrogen is low in the medium, the activity of nicotinamide adenine dinucleotide isocitrate dehydrogenase (NAD-IDH) decreases then tricarboxylic acid cycle is repressed, metabolism pathway altered, and protein synthesis stopped and lipid accumulation activated [25].

However, compared of process product yield $\left(Y_{P / S}\right)$ in batch fermentation at high $\mathrm{SJH}$ concentration more than $60 \mathrm{~g} / \mathrm{L}$, it was obvious that increase of $\mathrm{SJH}$ concentration resulting in decrease of this kinetic parameter, suggesting to difficult for up-scaling of lipid production by microalgae due to high substrate consumption rate and high concentration of $\mathrm{SJH}$ as carbon substrate with lower level of nitrogen source could be effect the cell growth, because nitrogen source supported the cell growth, thus, depleted of nitrogen may result to low biomass, suggesting that further fed-batch fermentation should investigated with initial nitrogen-rich medium to obtain high biomass at the early stage of exponential growth phase, then high concentration of carbon source will feed onto culture medium for stimulate the cellular lipid accumulation. Xiong et al. (2008) reported that biomass density of Chlorella protothecoides achieved was $16.8 \mathrm{~g} / \mathrm{L}$ in $184 \mathrm{~h}$ by performing fed-batch culture with lipid content of $50.3 \%$ dry cell weight using glucose as carbon substrate [26].

\section{CONCLUSIONS}

This study shows that isolated freshwater microalgae Chlorella sp. KKU-S2 was able to use sugarcane thick juice hydrolysate as carbon substrate for heterotrophic growth and high cell densities and lipid accumulation were found. In further works, optimizing of culture condition for increasing of biomass and lipid yields will be studied by using statistically such as respond surface methodology and fed-batch cultivation modes and then completed with the production of biodiesel from oil containing-microalgae biomass by direct transesterification. In addition, potential alternative sources of carbon substrate such as wastes or by-product from agro-industries might also provide an optimal way to reduce the production cost of biodiesel feed stocks. Process engineering that leads to a higher lipid productivity and cellular lipid content may also contribute in this regard. Thus, to realize the up-scaling production of biodiesel from microbial oils, it was necessary to obtain a large amount of biomass and lipid content as well as the low cost of cultivation process.

\section{REFERENCES}

[1] A. L. Ahmad, N. H. M. Yasin, C. J. C. Derek, and J. K. Lim, "Microalgae as a sustainable energy source for biodiesel production: A review," Renewable and Sustainable Energy Reviews, vol. 15, pp. 584-593, 2011.
[2] G. H. Huang, F. Chen, D. Wei, X. W. Zhang, and G. Chen. "Biodiesel production by microalgal biotechnology," ApplEnerg, vol. 87, pp. 38-46, 2010.

[3] L. Brennan and P. Owende, "Biofuels from microalgae-a-review of technologies for production, processing, and extractions of biofuels and co-products," Renew Energ. Rev., vol. 14, pp. 557-577, 2010.

[4] C.-Y. Chen, K. L. Yeh, R. Aisyah, D. J. Lee, and J. S. Chang, "Cultivation, photobioreactor design and harvesting of microalgae for biodiesel production: A critical review," Bioresour. Technol., vol. 102, no. 1, pp.71-81, 2011.

[5] H. Yu, S. Jia, and Y. Dai, "Growth characteristics of the cyanobacterium nostoc flagelliforme in photoautotrophic, mixotrophic and heterotrophic cultivation," J. Appl. Phycol., vol. 21, no. 1, pp. 127-133, 2009.

[6] N. Sun, Y. Wang, Y. T. Li, J. C. Huang, and F. Chen, "Sugar-based growth, astaxanthin accumulation and carotenogenic transcription of heterotrophic Chlorella zofingiensis (Chlorophyta)," Process Biochem, vol. 43, pp. 1288-1292, 2008.

[7] P. F. Ip and F. Chen, "Production of astaxanthin by the green microalga Chlorella zofingiensis in the dark," Process Biochem., vol. 40, pp. 733-738, 2005.

[8] X. Miao and Q. Wu, "Biodiesel production from heterotrophic microalgal oil,"Bioresour Technol., vol. 97, pp. 841-846, 2006.

[9] X. Li, H. Y. Hu, K. Gan, and Y. X. Sun, "Effect of different nitrogen and phosphorus concentration on the growth, nutrient uptake, and lipid accumulation of a freshwater microalga Scenedesmus sp.," Bioresour Technol., vol. 101, pp. 5494-5500, 2010.

[10] Y. Li, M. Horsman, B. Wang, N. Wu, and C. Q. Lan, "Effects of nitrogen sources on cell growth and lipid accumulation of green alga Neochloris oleoabundans," Appl. Microbiol. Biotechnol., vol. 81, pp. 629-636, 2009.

[11] S. M. Shi, Y. Jiang, and F. Chen, "High-yield production of lutein by the green microalga Chlorella protothecoides in heterotrophic fed-batch culture," Biotechnol. Prog., vol. 18, pp. 723-727, 2002.

[12] R. Leesing and N. Nontaso, "Microalgal oil production by green microalgae under heterotrophic cultivation," KKU Res J., vol. 9, pp. 787-793, 2010.

[13] B. Singh, A. Guldhe, I. Rawat, and F. Bux, "Towards a sustainable approach for development of biodiesel from plant and microalgae," Renew. Sustain. Energy Rev., vol. 29, pp. 216-245, 2014.

[14] D. Pimentel andT.W. Patzek, "Ethanol production using corn, switch grass, and wood; diesel production using soybean and sunflower," Natural Resources Research, vol. 14, pp. 65-76, 2005.

[15] T. Heredia-Arroyo, W. Wei, R. Ruan, and B. Hu, "Mixotrophic cultivation of Chlorellavulgaris and its potential application for the oil accumulation from non-sugar materials," Biomass Bioenergy, vol. 35, pp. 2245-2253, 2011.

[16] F. Y. Feng, W. Yang, G. Z. Jiang, Y. N. Xu, and T. Y. Kuang, "Enhancement of fatty acid production of Chlorella sp. (Chlorophyceae) by addition of glucose and sodium thiosulphate to culture medium," Process Biochem., vol. 40, pp. 1315-1318, 2005.

[17] O. Perez-Garcia, F. M. Escalante, L. E. de-Bashan, and Y. Bashan, "Heterotrophic cultures of microalgae: metabolism and potential products,"Water Res., vol. 45, no. 1, pp. 11-36, 2011.

[18] M. Wan, P. Liu, J. Xia, J. N. Rosenberg, G. A. Oyler, M. J. Betenbaugh, Z. Nie, and G. Qiu, "The effect of mixotrophy on microalgal growth, lipid content, and expression levels of three pathway genes in Chlorella sorokiniana,"Appl. Microbiol. Biotechnol., vol. 3, pp. 835-844, 2011.

[19] W. Xiong, C. Gao, D. Yan, C. Wu, and Q. Wu, "Double $\mathrm{CO}_{2}$ fixation in photosynthesis-fermentation model enhances algal lipid synthesis for biodiesel production," Bioresour. Technol., vol. 101, pp. 2287-2293.

[20] W. Jiang, J. Zhao, Z. Wang, and S. T. Yang, "Stable high-titer n-butanol production from sucrose and sugarcane juice by Clostridium acetobutylicumJB200 in repeated batch fermentations," Bioresource Technology, vol. 163, pp.172-179, 2014.

[21] G. L. Miller, "Use of dinitrosalicylic acid reagent for determination of reducing sugar," Anal Chem, vol. 31, pp. 426-432, 1959.

[22] D. Y. Kwon and J. S. Rhee, "A Simple and rapid colorimetric method for determination of free fatty acids for lipase assay," $\mathrm{J}$ Am Oil ChemSoc, vol. 63, pp. 89-92, 1986.

[23] L. F. Wu, P. C. Chen, and C. M. Lee, "The effects of nitrogen sources and temperature on cell growth and lipid accumulation of microalgae," International Biodeterioration \& Biodegradation, vol. 85, pp. 506-510, 2013.

[24] Y. Liang, N. Sarkany, and Y. Cui, "Biomass and lipid productivities of Chlorella vulgarisunder autotrophic, heterotrophic and mixotrophic growth conditions," Biotechnol. Lett., vol. 31, pp. 1043-1049, 2009.

[25] C. Ratledg and J. P. Wynn, "The biochemistry and molecular biology oflipid accumulation in oleaginous microorganisms," Adv. Appl. Microbiol., vol. 51, pp. 1-51, 2002. 
[26] W. Xiong, X. Li, J. Xiang, and Q. Wu, "High-density fermentation of microalga Chlorella protothecoidesin bioreactor formicrobio-diesel production," Appl. Microbiol. Biotechnol, vol. 78, pp. 29-36, 2008.

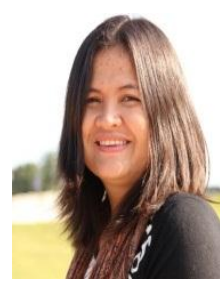

Supaporn Kookkhunthod got her bachelor of science degree in microbiology from Khon Kaen University, Khon Kaen, Thailand. Currently she is a master degree student at the Department of Microbiology, Faculty of Science, Khon Kaen University, Khon Kaen, Thailand Her master research study area is focusing on cultivation of microalgae for biomass and lipid production and microalgae-based biodiesel production.

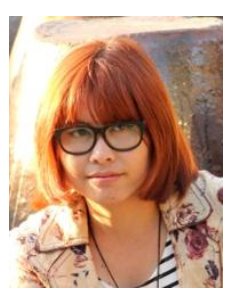

Rattanaporn Baojungharn received her bachelor of science degree in microbiology from Khon Kaen University, Khon Kaen, Thailand. She is now a master student at the Department of Microbiology, Faculty of Science, Khon Kaen University, Thailand. Her research interest for master study is production of biomass and lipid from the oleaginous yeast and biodiesel preparation from microbial oil.

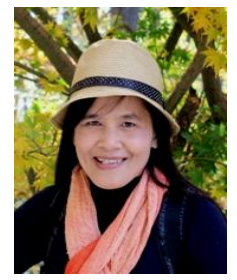

Ratanaporn Leesing is an assistant professor in the Department of Microbiology, Faculty of Science, Khon Kaen University, Khon Kaen, Thailand. She obtained the B.Sc. degree in biology-microbiology from Khon Kaen University, Khon Kaen, Thailand She received the M.Sc. degree in biotechnology from King Mongkut's University of Technology Thonburi, Bangkok, Thailand and graduated with a Ph.D. degree in food sciences from the University of Montpellier II, Montpellier, France. Her recent research interest and teaching activities are in the field of bio-resources, bio-energy and fermentation technology. 